\title{
Geometry and energy of amidoenethiolate conformers formed by ring-opening of several thiazolium ions in base: a theoretical study using density functional theory
}

\author{
Belquis Mothana, Trevor A. Bourgeois, Rebecca M. Longley, Geri-Lynn Devereaux, \\ Robert S. McDonald, and Katherine Valenta Darvesh* \\ Department of Chemistry, Mount Saint Vincent University, Halifax, Nova Scotia, Canada, B3M \\ 2J6 \\ E-mail: Katherine.Darvesh@msvu.ca
}
Dedicated to Oswald S. Tee on the occasion of his $60^{\text {th }}$ birthday, and in recognition of his many contributions to chemistry in Canada
(received 15 Sep 01; accepted 17 Nov 01; published on the web 25 Nov 01)

\begin{abstract}
An interesting aspect of the ring-opening of thiamine and certain other thiazolium ions is the biphasic kinetics of the ring reclosure process. It has previously been proposed that the two amide rotamers of the ring-opened amidoenethiolates are responsible for the two kinetic processes. We have carried out Hartree-Fock and density functional theory calculations on a series of amidoenethiolates and their corresponding tetrahedral intermediates. The corrected gas phase energy difference of $14.6 \mathrm{~kJ} / \mathrm{mol}$ between 1 'c and 2 'c supports the notion that the two rotamers can exist in solution in sufficient quantities to give rise to two kinetic processes. The major enethiolate conformer should cyclize more rapidly (after protonation) than the minor conformer in agreement with previous observations. The most stable tetrahedral intermediate has a geometry that suggests stabilization by the anomeric effect.
\end{abstract}

Keywords: Anomeric effect, amidoenethiolate, thiazolium ions, theoretical study, density functional theory

\section{Introduction}

Thiamine (Vitamin $\mathrm{B}_{1}$ ), or its pyrophosphate, has an important biochemical role as a cofactor in many enzymatic processes. ${ }^{1}$ Its key structural feature is a quaternary thiazolium ion, which is crucial to its catalytic functions. This ring and other thiazolium ions undergo reversible ringopening in aqueous solution. ${ }^{2}$ This $\mathrm{pH}$-dependent equilibrium (Scheme 1$)^{3}$ favours the quaternary ion $\left(\mathrm{Q}^{+}\right)$at low $\mathrm{pH}$ and the ring-opened enethiolate $\left(\mathrm{ETh}^{-}\right)$at high $\mathrm{pH}$, with the pseudobase $\left(\mathrm{T}^{\circ}\right)$ 
being the logical intermediate. ${ }^{2,4}$

Over forty years of kinetic studies on this equilibrium have revealed the principal steps in the interconversion. The ring-opening reaction is simply first order in both substrate and base. However, the ring-closing reaction is considerably more complex; biphasic kinetics are observed. $^{3,4 a, 4 b, 4 n, 40,5}$ Earlier workers attributed the faster process to the formation of pseudobase ${ }^{4 \mathrm{n}}$ or its N-protonated form ${ }^{4 \mathrm{a}, 4 \mathrm{~b}, 5}$ and the slower process to its breakdown to the thiazolium ion. More recently, however, spectroscopic (UV and NMR) evidence ${ }^{3}$ has been used to support the proposal that the two kinetic processes arise from the two amide conformers of the enethiol which show different propensity to cyclize.

Although, due to their lability, the enethiol conformers cannot be directly observed in aqueous solution, those of the enethiolates can be readily observed (in base) by NMR spectroscopy. ${ }^{3,4 c, 4 e, 6}$ All enethiolates studied which were derived from thiazolium ions without a $\mathrm{C}(2)$-substituent exist in a major:minor ratio of approximately $3: 1 .^{3}$ Further evidence from UV and NMR kinetic studies reveals that the enethiol derived from the major conformer gives rise to the fast kinetic process while the minor conformer is responsible for the slow process. Both kinetic processes produce the thiazolium ion; no intermediate can be detected.

These authors ${ }^{3}$ presented the structures of the enethiolate conformers as shown in Scheme 2, where conformer 1 would be expected to be the major conformer and, on protonation, to give rise to the faster reacting enethiol.
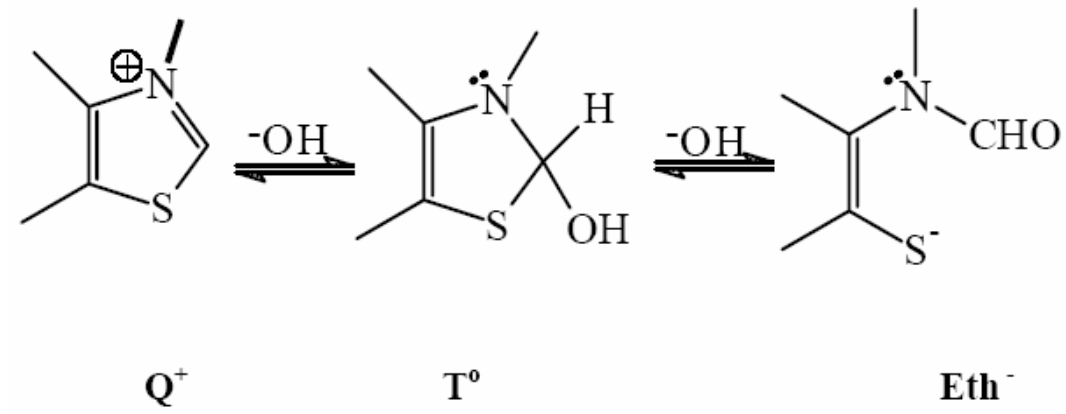

Scheme 1 Ring-opening of thiazolium ions

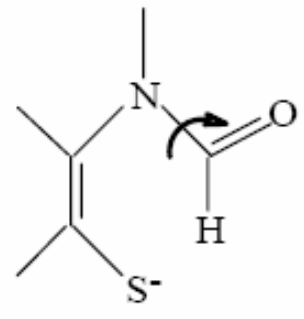

1

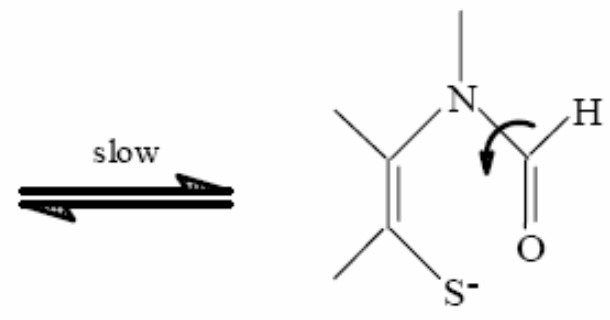

2

Scheme 2 Rotational isomers of the ring-opened amidoenethiolate, related by slow rotation about the $\mathrm{C}-\mathrm{N}$ bond of the amide group ${ }^{3}$ 
Spectroscopic studies, however, give no structural information about the rotamers, so that the question arises: do the structures of $\mathbf{1}$ and $\mathbf{2}$ given above accurately represent the enethiolate rotamers? In an attempt to address this question, a series of ring-opened enethiolate systems and their corresponding tetrahedral intermediates have been subjected to theoretical study: first, in order to obtain the geometries and relative energies of the enethiolate rotamers and second, in order to locate the tetrahedral intermediate into which they transform. The ring-opened enethiolates have additional significance because of their potential ability to be transported across cell membranes in the ring-opened form or as the disulfide. ${ }^{4 \mathrm{e}}$ A greater understanding of the properties of the enethiolates and their corresponding tetrahedral intermediates should help to shed light on this complicated mechanism.

\section{Methods}

The Gaussian suite of software (Gaussian 94 and 98) was employed throughout this study. ${ }^{7,8}$ Optimizations were carried out for the model systems represented in Figure 1. Structures 1 and 2 interconvert via rotation about the amide N-CO bond. Similarly, $\mathbf{3}$ and $\mathbf{4}$ are related via rotation about the amide N-CO bond. Structures 1 and $\mathbf{4}$ interconvert via the ethylenic C-N rotation, as do structures $\mathbf{2}$ and $\mathbf{3}$. The interconversions between $\mathbf{1}$ and $\mathbf{4}$, and between $\mathbf{2}$ and $\mathbf{3}$, are shown in Figure 1 with connecting lines. The initial search for minima on the potential surface was carried out at the HF/6-31+G* level, diffuse functions being deemed necessary for correct treatment of the anion. ${ }^{9}$ Neutral systems were examined at the HF/6-31G* level. The use of different basis sets for the anionic amidoenethiolates and the neutral tetrahedral intermediates is justified on the grounds that no interspecies energetic comparisons were made. Subsequently, optimizations were repeated at the B3LYP/6-31+G* level $^{10}$ (again, without diffuse functions for the neutral systems), starting with minima obtained at the Hartree-Fock level. Geometry optimizations were followed by a frequency analysis at the same level of theory as was used for the optimizations. The zero point energy (ZPE) was scaled by the empirical factor 0.96 for the correction to the reported energies, in accordance with Curtiss et al. ${ }^{11}$ 


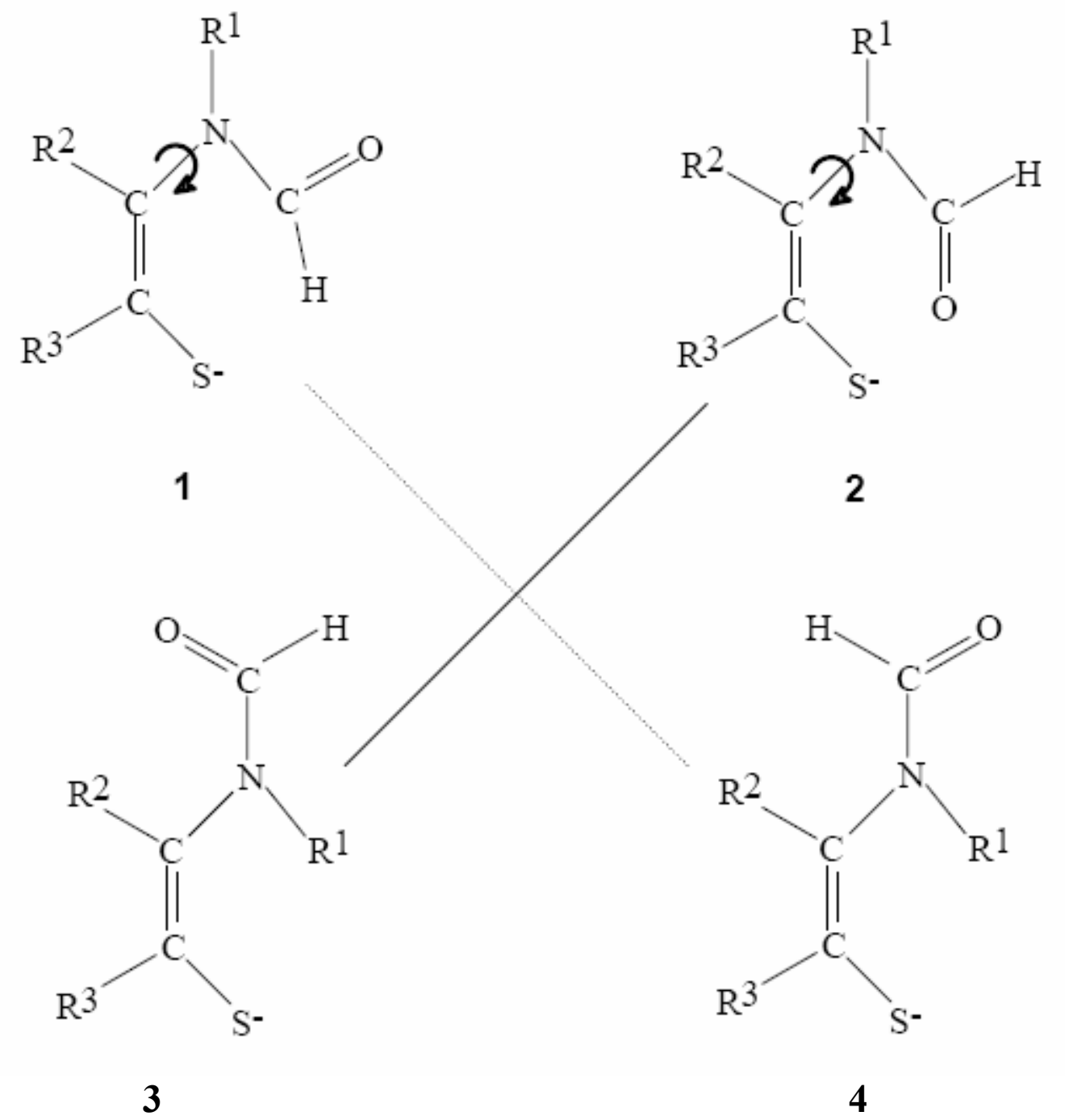

Figure 1. (a) $\mathrm{R}^{1}=\mathrm{R}^{2}=\mathrm{R}^{3}=\mathrm{H}$; (b) $\mathrm{R}^{1}=\mathrm{CH}_{3}, \mathrm{R}^{2}=\mathrm{R}^{3}=\mathrm{H}$; (c) $\mathrm{R}^{1}=\mathrm{R}^{2}=\mathrm{R}^{3}=\mathrm{CH}_{3}$.

\section{Results and Discussion}

\section{Amidoenethiolates}

a: $\mathbf{R}^{1}=\mathbf{R}^{2}=\mathbf{R}^{3}=\mathbf{H}$

Although four stationary points could be obtained by carrying out optimizations of rotamers 1-4 restricted to planar symmetry, in fact 1a and 2a were each found to possess one imaginary frequency at the Hartree-Fock level; therefore, they were not considered to be true minima on the potential surface. The only true HF minima are 3a and 4a, shown in Figure 2, with geometries and charges. In this figure, and in subsequent cases, note the short amide N-CO bond (1.346 X compared with $1.407 \mathrm{X}$ for the ethylenic $\mathrm{C}-\mathrm{N}$ bond in structure 3a). The corrected energy difference was found to be $6.40 \mathrm{~kJ} / \mathrm{mol}$ (see Table 1). (For brevity, only B3LYP numbers are 
included in the tables, figures and discussion. The Hartree-Fock results were not sufficiently different to warrant inclusion).

\section{b: $\mathbf{R}^{1}=\mathbf{C H} 3, \mathbf{R}^{2}=\mathbf{R}^{3}=\mathbf{H}$}

In the N-methyl case, no planar minimum on the potential surface could be found at the HartreeFock level. The only true minima arise from a twist of the ethylenic C-N single bond (Figure 3). Clearly, a clockwise or counterclockwise twist is possible. The corrected energy difference of $8.77 \mathrm{~kJ} / \mathrm{mol}$ is reported in Table 1. The energetically most favoured rotamer (1'b) looks essentially like what we refer to as Structure 1 of Scheme 2, but twisted about the ethylenic C-N bond by $131^{\circ}$, as measured by the CCNC (carbonyl carbon) dihedral angle. The less favoured rotamer $\left(\mathbf{2}^{\prime} \mathbf{b}\right)$ looks more like our Structure 2, but twisted out of plane by $154^{\circ}$. Why is $\mathbf{1}^{\prime} \mathbf{b}$ the more favoured rotamer? As mentioned earlier, $\mathbf{1}$ and $\mathbf{2}$ are related by rotation about the amide $\mathrm{N}$ $\mathrm{CO}$ bond. In the planar form of 2 represented in Figure 1, the oxygen of the carbonyl and the sulfide are required to be in close proximity. As they both bear negative charges (see Figure 3), this is energetically unfavourable. The proximity of negative charges in the planar conformation also explains why $\mathbf{2}$ has a greater tendency than $\mathbf{1}$ to exhibit a large out-of-plane twist. Note that the nitrogen has not lost its $\mathrm{sp}^{2}$ character in this loss of Cs symmetry: this is not surprising, considering the characteristics of the amide bond. The addition of a methyl group at the nitrogen has altered the atomic charge picture, leaving the charges on the nitrogen and on the sulfur less negative than they were for the least substituted rotamers shown in Figure 2.

\section{c: $\mathbf{R}^{1}=\mathbf{R}^{2}=\mathbf{R}^{3}=\mathbf{C H 3}$}

Once again, as was the case for N-methyl, no planar minimum could be found at the HartreeFock level. Now the most favoured rotamer (1'c) resembles structure 1, but twisted to such an extent so as to make the S-C-C and C-N-C planes virtually orthogonal (see Figure 4). The CCNC (carbonyl carbon) dihedral angle has decreased from $131^{\circ}$ to $97^{\circ}$. This leads to a rotamer virtually halfway between $\mathbf{1}$ and $\mathbf{4}$. The less favourable rotamer $\left(\mathbf{2}^{\prime} \mathbf{c}\right)$ is also twisted to a lesser extent than its $\mathrm{N}$-methyl counterpart, when the same dihedral angle is considered; however, it all depends on the point of view. The N-methyl case known as $\mathbf{2}^{\prime} \mathbf{b}$ can be thought of as structure $\mathbf{2}$, twisted out of plane by $154^{\circ}$. A full twist of $180^{\circ}$ would take it all the way to structure 3 . The trimethyl case $\mathbf{2}^{\prime} \mathbf{c}$ is halfway between $\mathbf{2}$ and $\mathbf{3}$, which minimizes steric repulsions due to the bulky methyl groups. The corrected energy difference of $14.63 \mathrm{~kJ} / \mathrm{mol}$ is the largest difference reported of all the model systems (Table 1). Presumably the differences have become more pronounced due to the relative bulk of the methyl substituents. The magnitude of the energy difference is plausible. The NMR studies found slowly interconverting enethiolates in a ratio of about $3: 1{ }^{3}$ Our energy difference would suggest a higher ratio; however, solvent effects should reduce this difference considerably.

The enethiolates were previously represented according to Scheme 2. Our rotamers, by contrast, are not planar. However, as predicted, the major rotamer is the one we call 1'; the rotamer related to structure 1 by a twist of the ethylene $\mathrm{C}-\mathrm{N}$ single bond shown twisting in 
Figure 1, and the minor rotamer is the one we call 2', which can end up as structure 2 via the ethylene $\mathrm{C}-\mathrm{N}$ single bond twist. A final note on atomic charges: the nitrogen in the fully substituted case $\mathbf{1}^{\prime} \mathbf{c}$ is the least negative of the model systems, bearing a charge of +0.06 . The sulfur of 1'c, while still negative, only bears a charge of -.43 , which is less negative than in the less substituted counterparts.

The ring-opened enethiolate $\mathbf{1}^{\prime} \mathbf{c}$ is lower in energy than $\mathbf{2}^{\prime} \mathbf{c} . \mathbf{1}^{\prime} \mathbf{c}$ also appears to be poised for cyclization, based on its appearance in Figure 4 and on its relatively short S-C (carbonyl carbon) distance of $3.763 \mathrm{X}$, as compared with a corresponding distance of 4.039 Xin its 2'c counterpart. Assuming no significant conformational change between the thiolate and its protonated thiol, we can ascribe the faster process to the most favoured rotamer, and the slower process to its less favoured counterpart.

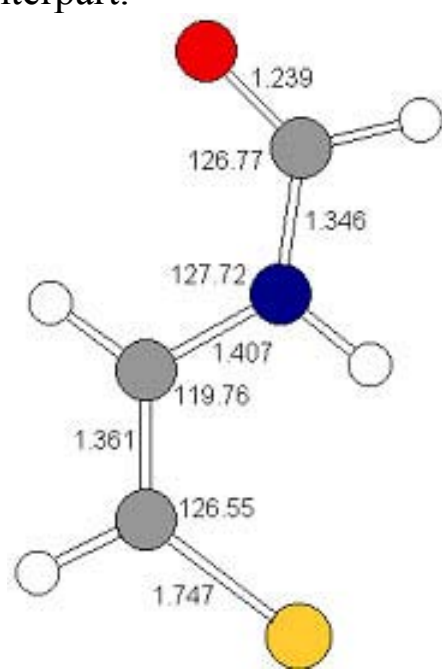

3a

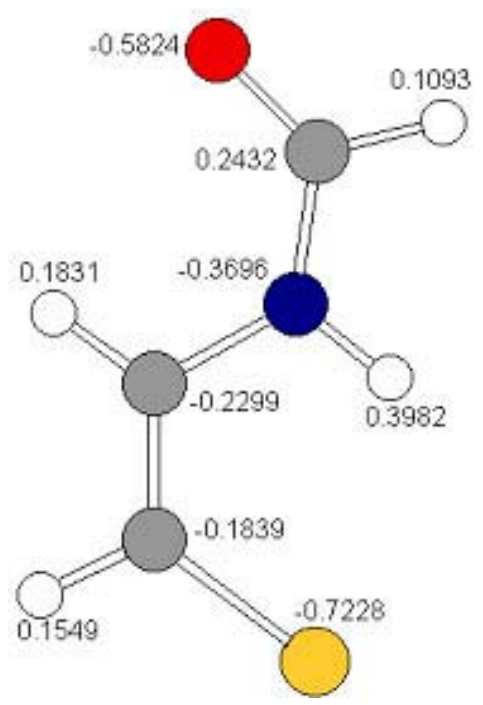

$3 a$

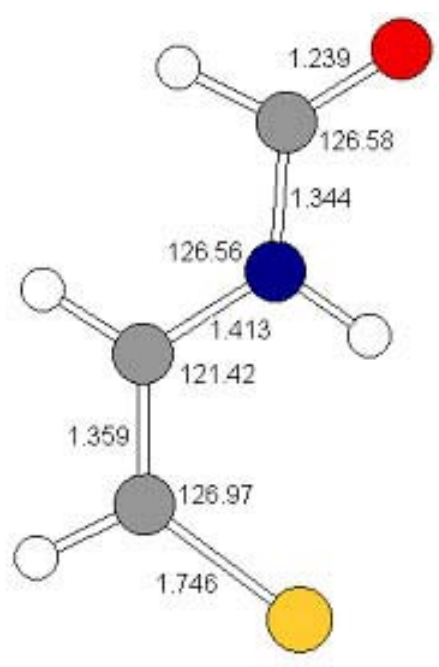

geometry

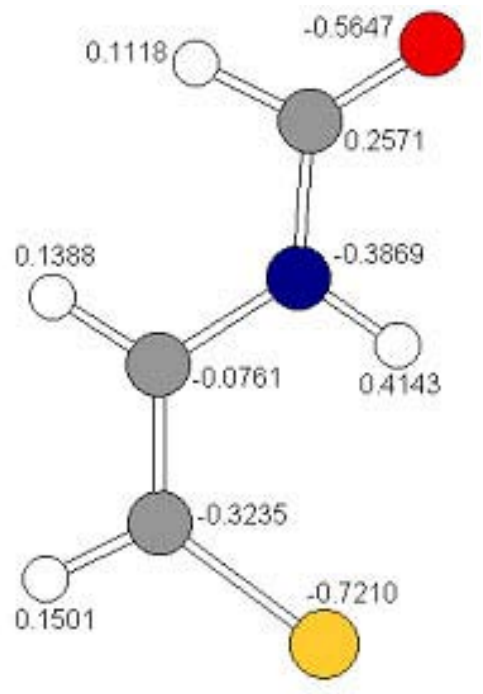

$4 a$

Figure 2. B3LYP Optimized structures for a, including bond lengths and charges (obtained by Mulliken population analysis). 

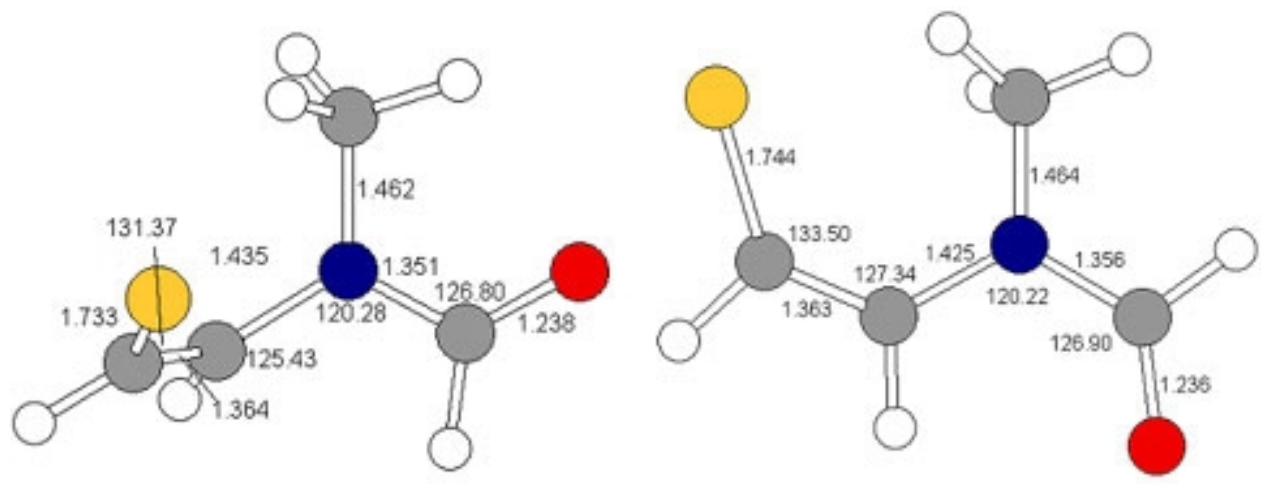

1'b

geometry

$\mathbf{2}^{\prime} \mathbf{b}$
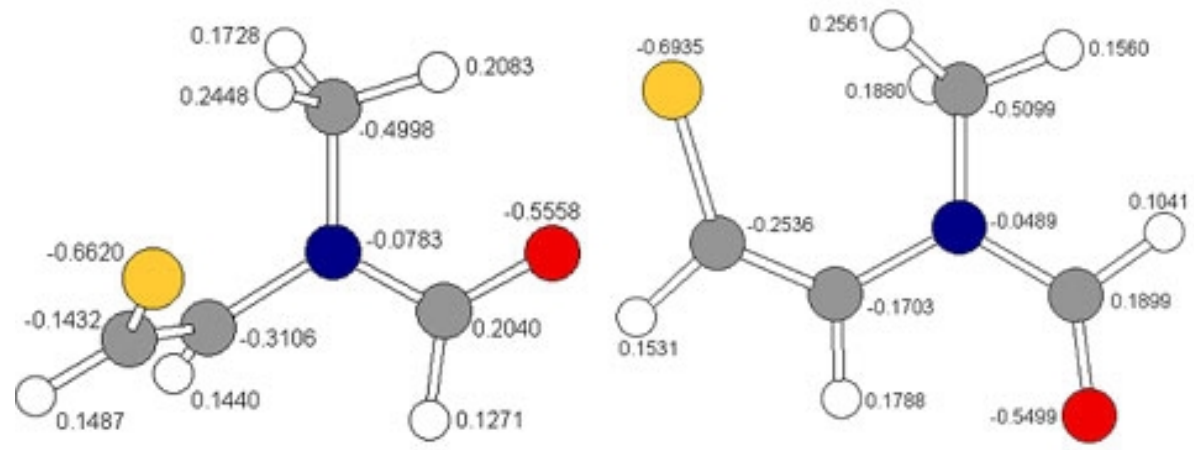

1'b

charges

2'b

Figure 3. B3LYP Optimized structures for $\mathbf{b}$, including bond lengths and charges (obtained by Mulliken population analysis). 

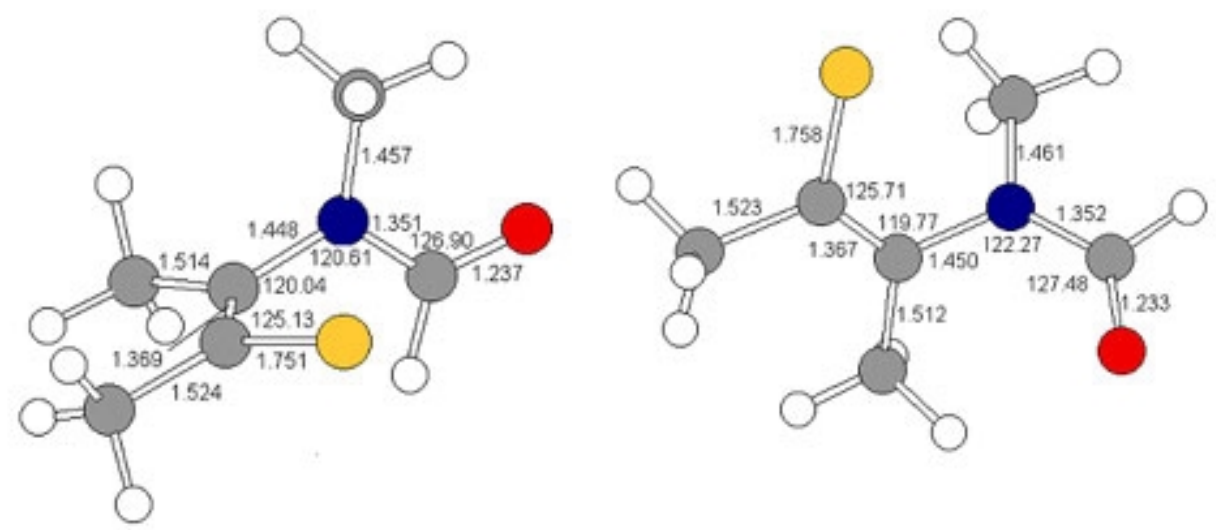

$1 ' c$

geometry

2 'c
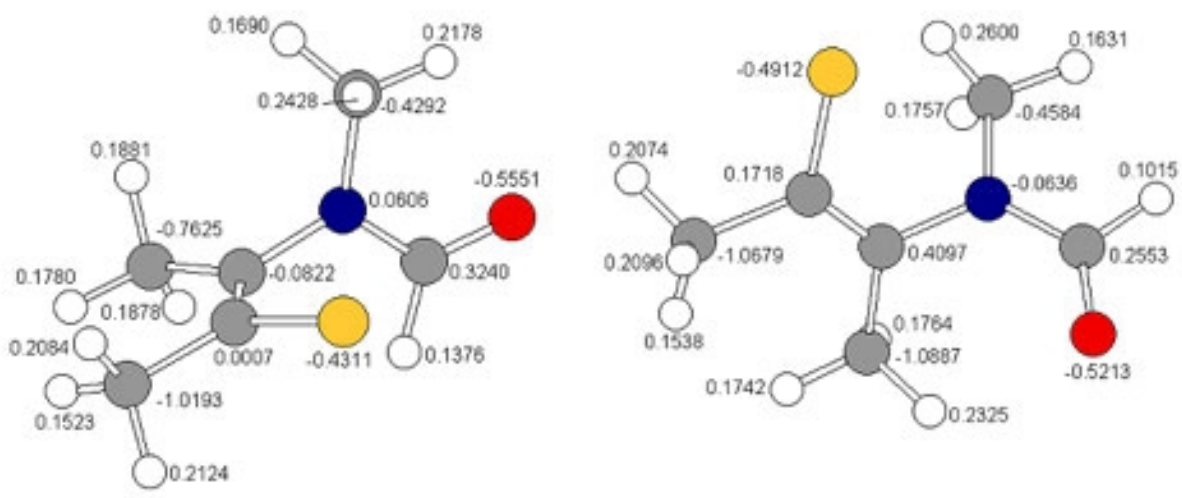

1 'c

charges

2'c

Figure 4. B3LYP Optimized structures for c, including bond lengths and charges (obtained by Mulliken population analysis).

Table 1. B3LYP total energies, unscaled ZPE corrections and relative energies for ring-opened amido enethiolates $\mathrm{a}, \mathrm{b}$, and $\mathrm{c}$

\begin{tabular}{ccccc}
\hline Compound & E total (Hartrees) & ZPE $(\mathrm{kJ} / \mathrm{mol})$ & $|\Delta \mathrm{E}|(\mathrm{kJ} / \mathrm{mol})$ & $\mathrm{dCCNC}^{\mathrm{a}}$ \\
\hline $\mathbf{3 a}$ & -644.96263 & 183.0 & 0.00 & $180^{\circ}$ \\
$\mathbf{4 a}$ & -644.95976 & 181.8 & 6.40 & $180^{\circ}$ \\
$\mathbf{1} \mathbf{b}$ & -684.26165 & 255.3 & 0.00 & $131^{\circ}$ \\
$\mathbf{2} \mathbf{\prime} \mathbf{1}$ & -684.25865 & 256.3 & 8.77 & $154^{\circ}$ \\
$\mathbf{1} \mathbf{c}$ & -762.89026 & 400.8 & 0.00 & $97^{\circ}$ \\
$\mathbf{2} \mathbf{c}$ & -762.88493 & 401.5 & 14.63 & $117^{\circ}$ \\
\hline
\end{tabular}

${ }^{\mathrm{a}} \mathrm{CCNC}$ (carbonyl carbon ) dihedral angle 


\section{Tetrahedral intermediates}

a: $\mathbf{R}^{1}=\mathbf{R}^{2}=\mathbf{R}^{3}=\mathbf{H}$

Optimized structures and charges for the tetrahedral intermediates of series a are shown in Figures $5 \mathrm{a}$ and 5b, respectively. As the hydroxy carbon is tetrahedral, enantiomers are a possibility. Only one of the two possible enantiomers is represented in Figure 5. There are three structural issues to be considered.

First, the hydrogens on the nitrogen and on the hydroxy carbon $\mathrm{C}_{2}$ can be cis or trans. Second, the $\mathrm{OH}$ can be axial or equatorial. Finally, the $\mathrm{OH}$ hydrogen can rotate. Exploring the potential surface, three minima were found. $\mathbf{T}^{\mathbf{0}} \mathbf{a}$ (axial, trans) had the lowest energy (Table 2). $\mathbf{T}^{\mathbf{0}} \mathbf{a}$ (axial, trans) is so named because " $\mathbf{a}$ " once again refers to the case $\mathrm{R}^{1}=\mathrm{R}^{2}=\mathrm{R}^{3}=\mathrm{H}$. Axial describes the $\mathrm{OH}$ orientation and trans describes the relative orientation of the hydrogens on the nitrogen and on the hydroxy carbon. Other structures obtained were $\mathbf{T}^{\mathbf{0}} \mathbf{a}$ (equatorial, cis) and $\mathbf{T}^{\mathbf{0}} \mathbf{a}$ (axial, cis). $\mathbf{T}^{\mathbf{0}} \mathbf{a}$ (equatorial, cis) can be obtained from $\mathbf{T}^{\mathbf{0}} \mathbf{a}$ (axial, trans) simply by interchanging the $\mathrm{H}$ and the $\mathrm{OH}$. However, it should be pointed out that, with a $\mathrm{C}-\mathrm{C}-\mathrm{N}-\mathrm{C}$ dihedral angle of only $4^{\circ}$, the designation "equatorial" in $\mathbf{T}^{\mathbf{0}} \mathbf{a}$ (equatorial, cis) becomes rather insignificant. On both of the aforementioned, the $\mathrm{OH}$ hydrogen points toward the center of the ring. The least favoured structure is $\mathbf{T}^{0} \mathbf{a}$ (axial, cis). Numerous attempts were made to locate the (equatorial, trans) counterpart: however, in all cases, the structure reverted to (axial, trans). Frequency calculations verified that all three species were true minima on the potential surface (i.e.: no imaginary frequencies were found). Why is the $\mathbf{T}^{\mathbf{0}} \mathbf{a}$ (axial, trans) structure the most stable? This is likely due to the anomeric effect, ${ }^{12,13}$ whereby the lone pair of the nitrogen antiperiplanar to the polar $\mathrm{C}-\mathrm{O}$ bond affords a modest stabilization. The fingerprint of the anomeric effect is a shortening of the central $\mathrm{C}-\mathrm{N}$ bond, and a lengthening of the $\mathrm{C}-\mathrm{O}$ bond. Referring to Figure 5a, one does observe that, although the central $\mathrm{C}-\mathrm{N}$ bonds are virtually identical, $\mathbf{T}^{\mathbf{0}} \mathbf{a}$ (axial,trans) has a longer $\mathrm{C}-\mathrm{O}$ separation than the corresponding separation of its (equatorial, cis) counterpart. This explains the stabilization of $3.40 \mathrm{~kJ} / \mathrm{mol}$ experienced by $\mathbf{T}^{\mathbf{0}} \mathbf{a}$ (axial, trans). Refer to Table 2 for a summary of the tetrahedral intermediates.

b: $\mathbf{R}^{1}=\mathbf{C H 3}, \mathbf{R}^{2}=\mathbf{R}^{3}=\mathbf{H}$

Figures $6 \mathrm{a}$ and $6 \mathrm{~b}$ show optimized structures and charges for the methyl-substituted tetrahedral intermediate, respectively. No imaginary frequencies were found. Once again $\mathbf{T}^{\mathbf{0}} \mathbf{b}$ (axial, trans) had the lowest energy, but only by $0.57 \mathrm{~kJ} / \mathrm{mol}$ (Table 2). Presumably the steric demands of the methyl group counteract to a large extent the stabilization due to the anomeric effect. A minimum for $\mathbf{T}^{\mathbf{0}} \mathbf{b}$ (axial, cis) could not be found at the Hartree-Fock level.

c: $\mathbf{R}^{1}=\mathbf{R}^{2}=\mathbf{R}^{3}=\mathbf{C H 3}$

Optimized structures are shown in Figures $7 \mathrm{a}$ and $7 \mathrm{~b}$ for the most highly substituted model systems. As in the less substituted tetrahedral intermediates, these were found to be minima on 
the potential surface: i.e., no imaginary frequencies were found. By now the energy difference between the two minima is negligible (Table 2), the steric effect of the methyl groups all but canceling any anomeric effect. Note the hydrogen of the $-\mathrm{OH}$ group points in toward the ring for both structures.

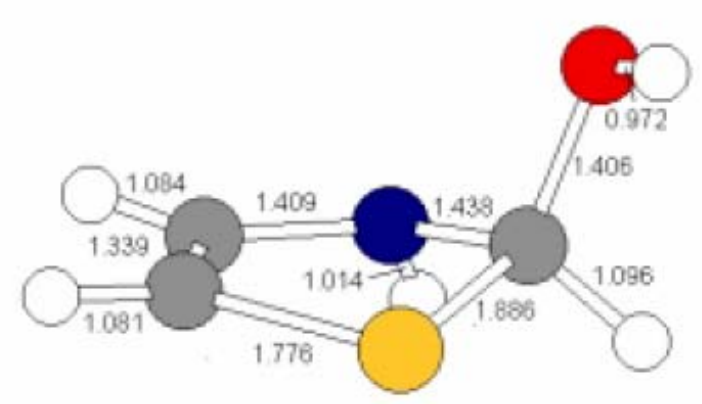

$\mathbf{T}^{\mathbf{0}} \mathbf{a}(\mathbf{a x i a l}, \mathbf{c i s})$

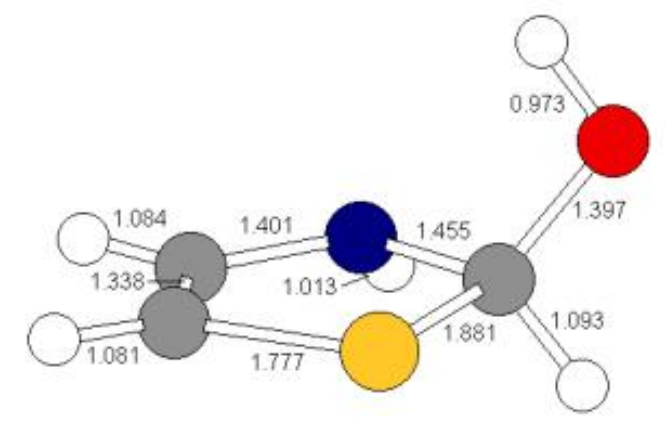

\section{$\mathbf{T}^{\mathbf{0}} \mathbf{a}(\mathbf{e q u a t o r i a l , ~ c i s )}$}

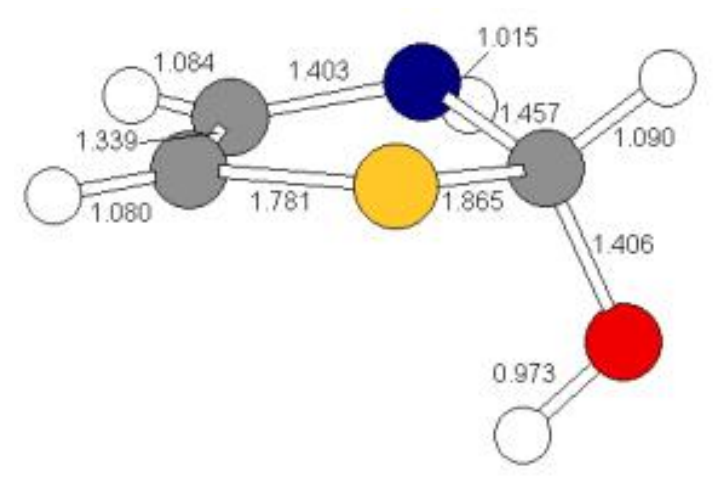

$T^{0} \mathbf{a}($ axial, trans)

Figure 5a. B3LYP Optimized structures for the tetrahedral intermediates of a. 


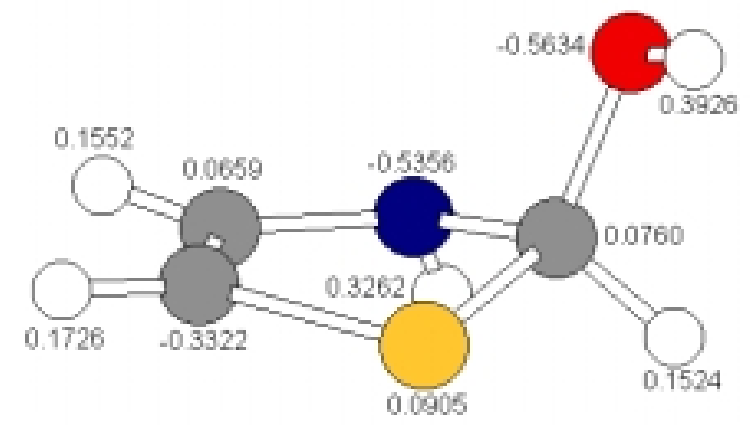

\section{T̃a (axial, cis)}

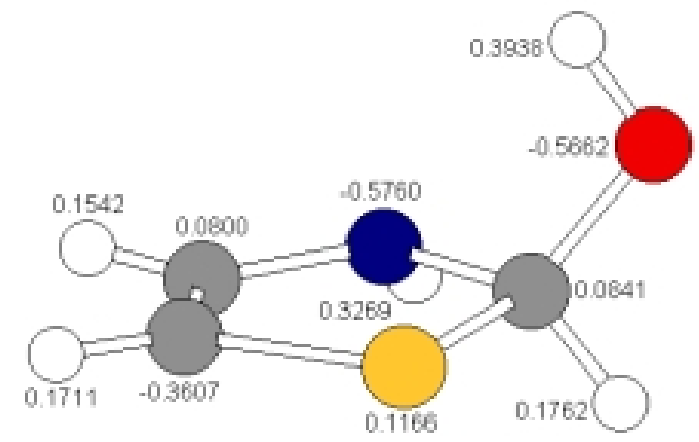

T'a (equatorial, cis)

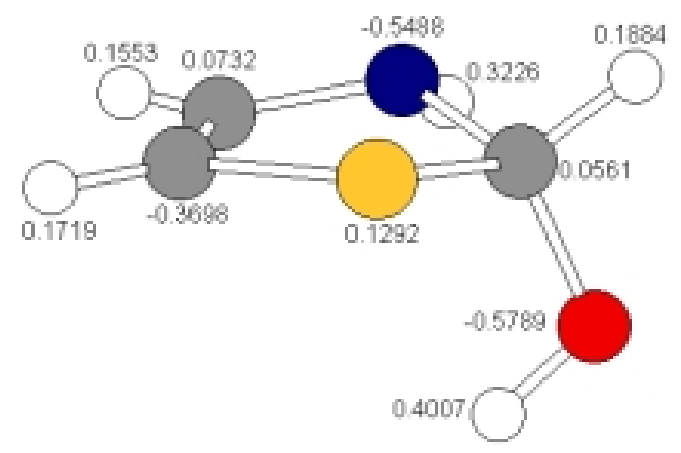

$\mathbf{T}^{\mathbf{0}} \mathbf{a}$ (axial, trans)

Figure 5b. B3LYP charges for the tetrahedral intermediates of $\mathbf{a}$. 


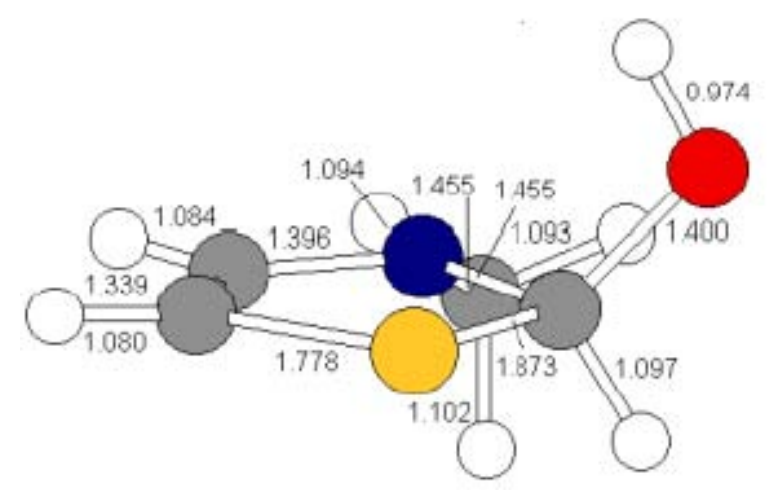

\section{$\mathbf{T}^{0} \mathbf{b}$ (equatorial, cis )}

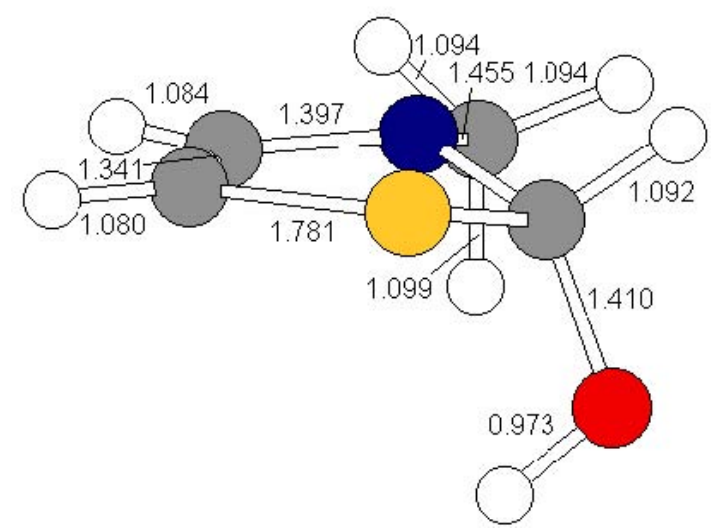

T:̃b (axial, trans)

Figure 6a. B3LYP Optimized structures for the tetrahedral intermediates of $\mathbf{b}$. 


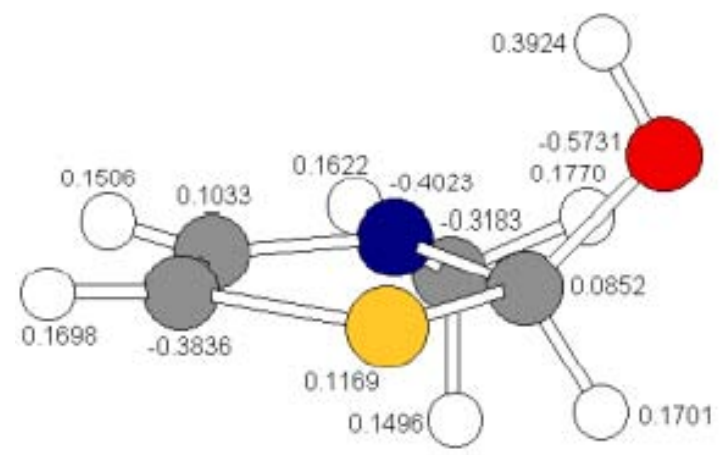

T:̃ b (equatorial, cis) $\mathbf{T}^{0} \mathrm{~b}$ (axial, trans)

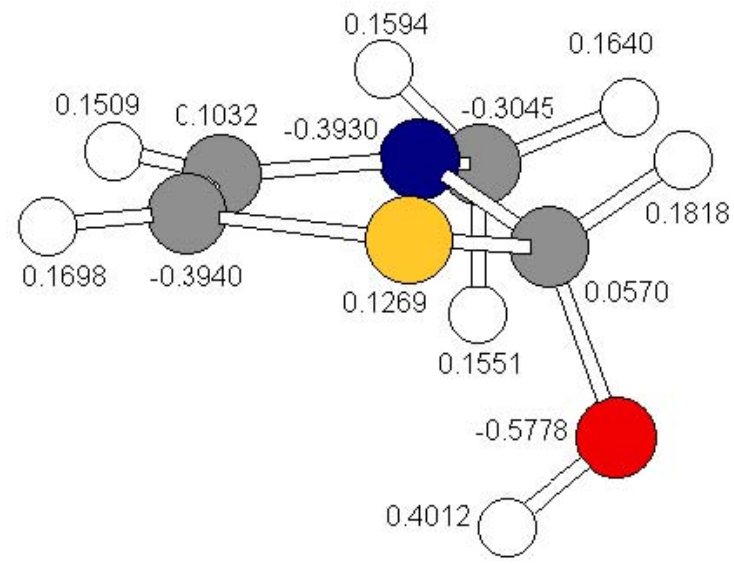

Figure 6b. B3LYP charges for the tetrahedral intermediates of $\mathbf{b}$. 


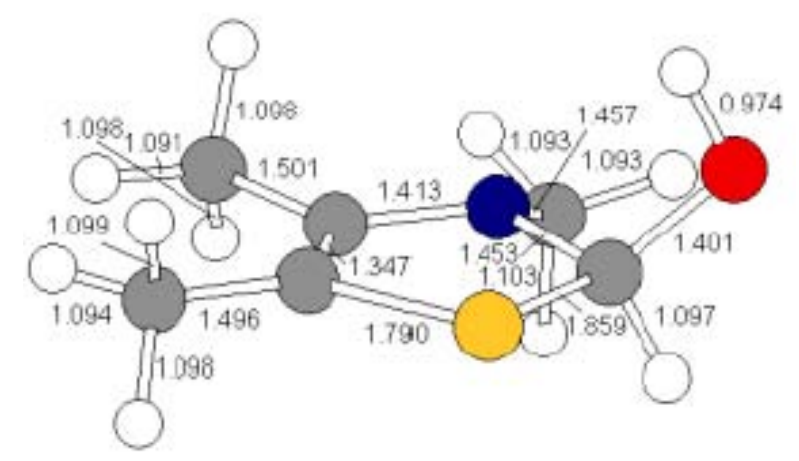

$\mathbf{T}^{\mathbf{0}} \mathbf{c}$ (equatorial, cis)

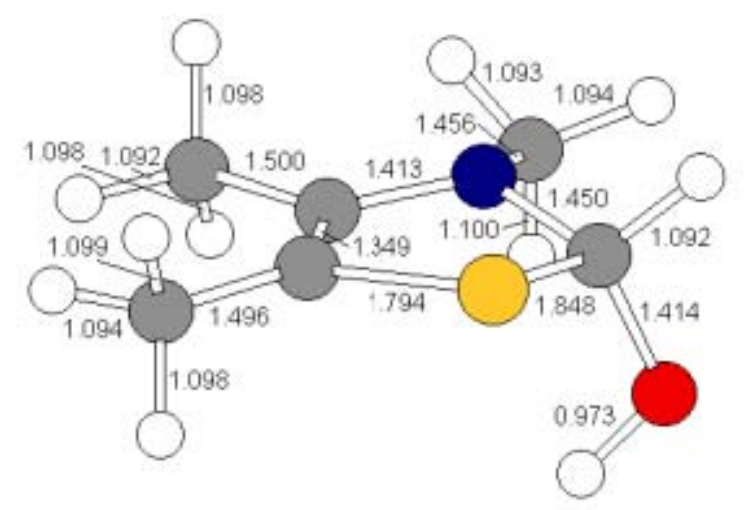

$T^{0} \mathrm{c}$ (axial, trans)

Figure 7a. B3LYP Optimized structures for the tetrahedral intermediates of $\mathbf{c}$. 


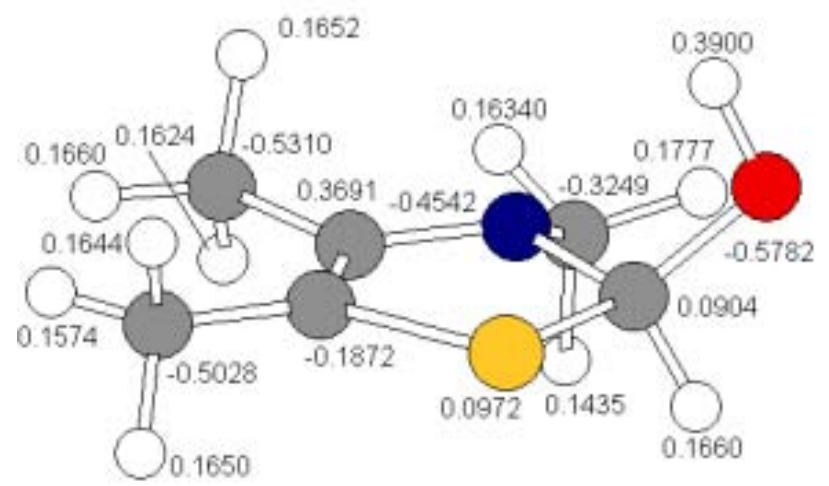

$\mathbf{T}^{\mathbf{0}} \mathrm{c}$ (equatorial, cis)

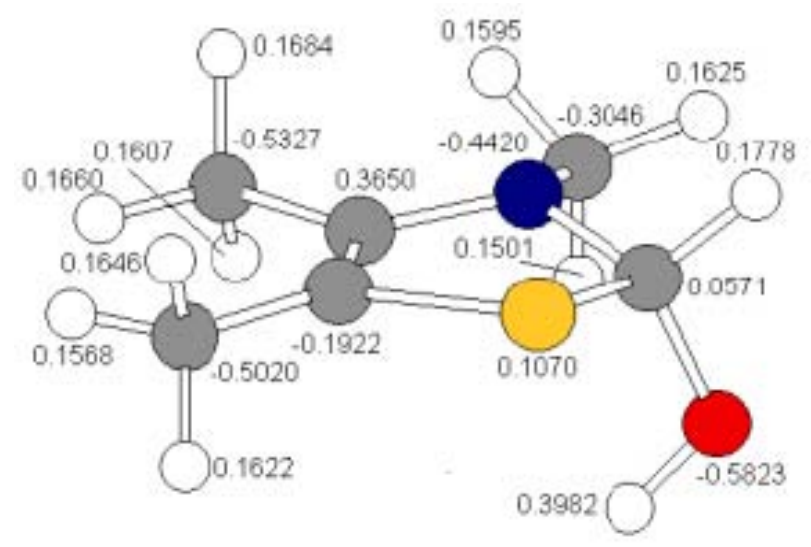

$\mathbf{T}^{\mathbf{0}} \mathrm{c}$ (axial, trans)

Figure 7b. B3LYP charges for the tetrahedral intermediates of $\mathbf{c}$. 
Table 2. B3LYP energies relative to the lowest structural isomer for tetrahedral intermediates

\begin{tabular}{cccc}
\hline Compound & E total (hartrees) & $\mathrm{ZPE}(\mathrm{kJ} / \mathrm{mol})$ & $\Delta \mathrm{E} \mid(\mathrm{kJ} / \mathrm{mol})$ \\
\hline $\mathbf{T}^{\mathbf{0}} \mathbf{a}$ (axial, trans) & -645.45291 & 218.1 & 0.00 \\
$\mathbf{T}^{\mathbf{0}} \mathbf{a}$ (equatorial, cis) & -645.45122 & 217.0 & 3.40 \\
$\mathbf{T}^{\mathbf{0}} \mathbf{a}$ (axial, cis) & -645.44544 & 216.0 & 17.62 \\
$\mathbf{T}^{\mathbf{0}} \mathbf{b}$ (axial, trans) & -684.76276 & 291.2 & 0.00 \\
$\mathbf{T}^{\mathbf{0}} \mathbf{b}$ (equatorial, cis) & -684.76238 & 290.8 & 0.57 \\
$\mathbf{T}^{\mathbf{0}} \mathbf{c}$ (axial, trans) & -763.40087 & 439.5 & 0.00 \\
$\mathbf{T}^{\mathbf{0}} \mathbf{c}$ (equatorial, cis) & -763.40082 & 439.3 & 0.25 \\
\hline
\end{tabular}

\section{Conclusions}

The two rotamers obtained via theoretical optimization can be related to the two rotational isomers of the ring-opened thiolate previously observed by NMR. Our results (Figures 2-4) support the notion that the two rotamers differ by rotation about the amide $\mathrm{N}-\mathrm{CO}$ bond. We also note that rotamer $\mathbf{2}^{\prime}$ exhibits a greater twist about the ethylenic $\mathrm{C}-\mathrm{N}$ bond than does rotamer $\mathbf{1}^{\prime}$ in all cases. All in all, $\mathbf{2}^{\prime}$ must undergo significant rotational realignment before ring closure of the protonated form can occur. This is consistent with $\mathbf{2}^{\prime}$ being responsible for the slower ring reclosure process. The full reaction profile for the closure of the ring-opened thiol to yield the tetrahedral intermediate could serve to identify which of the two possible tetrahedral intermediates is reached by each rotamer. A more detailed study of the potential energy surface remains as an interesting question for future consideration.

\section{Acknowledgements}

We thank NSERC for financial support through research grants and Undergraduate Student Research Associateships. We thank Mount Saint Vincent University for financial assistance. We acknowledge with gratitude the Killam Library of Dalhousie University. We thank Andrew Grant of Mount Allison University for his helpful comments. And finally, heartfelt thanks to Ossie Tee who has maintained an abiding interest in this subject. His support and encouragement throughout the duration of this work is greatly appreciated.

\section{References}

1. Nelson, D. L.; Cox, M. M. In Lehninger Principles of Biochemistry; Worth, 2000; pp 545546.

2. (a) Breslow, R. J. Am. Chem. Soc. 1958, 80, 3719. (b) Asahi, Y.; Nagaoka, M. Chem. 
Pharm. Bull. Jpn. 1971, 19, 1017. (c) Bunting, J. W. Adv. Heterocycl. Chem. 1979, 25, 1. (d) Nogami, H.; Hasegawa, J.; Rikihisa, T. Chem. Pharm. Bull. Jpn. 1973, 21, 858. (e) Zoltewicz, J. A.; Uray, G. J. Org. Chem. 1980, 45, 2104. (f) Kluger, R.; Chin, J.; Smyth, T. J. Am. Chem. Soc. 1981, 103, 884. (g) Washabaugh, M. W.; Yang, C. C.; Stivers, J. T.; Lee, K.-S. Bioorg. Chem. 1992, 20, 296. (h)Washabaugh, M. W.; Gold, M. A.; Yang, C. C. J. Am. Chem. Soc. 1995, 117, 7657.

3. Carmichael, E. C.; Geldart, V. D.; McDonald, R. S.; Moore, D. B.; Rose, S.; Colebrook, L. D.; Spiropoulos, G. D.; Tee, O. S. J. Chem. Soc., Perkin Trans. 2 1997, 2609.

4. (a) Heiber-Langer, I.; Winter, I.; Knoche, W. J. Chem. Soc. Perkin Trans. 2 1992, 1551. (b) Barrabass, S.; Heiber-Langer, I.; Knoche, W. J. Chem. Soc. Perkin Trans. 2 1994, 131. (c) Haake, P.; Duclos, J. M. Tetrahedron Lett. 1970, 461. (d) Asahi, Y.; Mizuta, E., Talanta 1972 19, 567. (e) Duclos, J. M.; Haake, P. Biochemistry 1974, 13, 5358. (f) Maier, G. D.; Metzler, D. E. J. Am. Chem. Soc. 1958, 79, 4386. (g) Hopmann, R. F. W.; Brugoni, G. P. Angew. Chem., Int. Ed. 1981, 20, 961. (h) Hopmann, R. F. W. Ann. N. Y. Acad. Sci 1982, 378, 32. (i) Washabaugh, M. W.; Yang, C. C.; Hollenbach, A. D.; Chen, P. Bioorg. Chem. 1993, 21, 170. (j) Zoltewicz, J. A.; Uray, G. Biorg. Chem.1994, 22, 1. (k) Mills, W. H.; Clark, L. M.; Aeschlmann, J. A. J. Chem. Soc. 1923, 2353. (1) Clark, L. M. J. Chem. Soc. 1928, 2313. (m) Hopmann, R. F. W.; Brugoni, G. P.; Fol, B. J. Am. Chem. Soc. 1982, 104, 1341. (n) El Hage Chahine, J. M.; Dubois, J.-E. J. Am. Chem. Soc. 1983, 105, 2355. (o) Tee, O. S.; Spiropoulos, G. D.; McDonald, R. S.; Geldart, V. D.; Moore, D. J. Org. Chem. 1986, 51, 2150. (p) El Hage Chahine, J. M.; Dubois, J.-E. J. Chem. Soc., Perkin Trans. 2 1988, 1409.

5. Hermann, J.; Knoche, W.; Neugebauer, R. J. Chem. Soc., Perkin Trans. 2 1995, 463.

6. Barletta, G. L.; Zou, Y.; Huskey, W. P.; Jordan, F. J. Am. Chem. Soc. 1997, 119, 2356.

7. Gaussian 94, Revision B.1: M. J. Frisch, G. W. Trucks, H. B. Schlegel, P. M. W. Gill, B. G. Johnson, M. A. Robb, J. R. Cheeseman, T. A. Keith, G. A. Petersson, J. A. Montgomery, K. Raghavachari, M. A. Al-Laham, V. G. Zakrzewski, J. V. Ortiz, J. B. Foresman, J. Cioslowski, B. B. Stefanov, A. Nanayakkara, M. Challacombe, C. Y. Peng, P. Y. Ayala, W. Chen, M. W. Wong, J. L. Andres, E. S. Replogle, R. Gomperts, R. L. Martin, D. J. Fox, J. S. Binkley, D. J. Defrees, J. Baker, J. J. P. Stewart, M. Head-Gordon, C. Gonzalez, and J. A. Pople, Gaussian Inc., Pittsburgh, PA, U. S. A., 1995.

8. Gaussian 98 (Revision A.9), M. J. Frisch, G. W. Trucks, H. B. Schlegel, G. E. Scuseria, M. A. Robb, J. R. Cheeseman, V. G. Zakrzewski, J. A. Montgomery, R. E. Stratmann, J. C. Burant, S. Dapprich, J. M. Millam, A. D. Daniels, K. N. Kudin, M. C. Strain, O. Farkas, J. Tomasi, V. Barone, M. Cossi, R. Cammi, B. Mennucci, C. Pomelli, C. Adamo, S. Clifford, J. Ochterski, G. A. Petersson, P. Y. Ayala, Q. Cui, K. Morokuma, D. K. Malick, A. D Rabuck, K. Raghavachari, J. B. Foresman, J. Cioslowski, J. V. Ortiz, B. B. Stefanov, G. Liu, A. Liashenko, P. Piskorz, I. Komaromi, R. Gomperts, R. L. Martin, D. J. Fox, T. Keith, M. A. Al-Laham, C. Y. Peng, A. Nanayakkara, C. Gozalez, M. Challacombe, P. M. W. Gill, B. G. Johnson, W. Chen, M. W. Wong, J. L. Andres, M. Head-Gordon, E. S. Replogle and J. A. 
Pople, Gaussian, Inc., Pittsburgh PA, 1998.

9. Simons, J.; Jordan, K. D. Chem. Rev. 1987, 87, 535.

10. Becke, A. D. J. Chem. Phys. 1993, 98, 5648.

11. Curtiss, L. A.; Raghavachari, K.; Redfern, P. C.; Pople, J. A. Chem. Phys. Lett. 1997, 270, 419.

12. Grein, F.; Deslongchamps, P. Can. J. Chem. 1992, 70, 604.

13. Von Rague Schleyer, P.; Kos, A. J. Tetrahedron 1983, 39, 1141. 